\title{
Effects of Laundering on Seaming Attributes of a Fabric for Public Basic school uniforms
}

\author{
Patience Danquah Monnie ${ }^{1}$, Docea Fianu ${ }^{2}$, Efua Vandyck ${ }^{2}$, Cynthia Gadegbeku ${ }^{2}$ \\ ${ }^{I}$ Department of Vocational and Technical Education, University of Cape Coast, Cape Coast, Ghana \\ ${ }^{2}$ Department of Family and Consumer Sciences, University of Ghana, Legon, Ghana
}

\begin{abstract}
Quality seams have great impact on the quality of garments. The study evaluated effect of laundering on plain seam in a suitable fabric for Ghanaian public basic school uniforms by varying sewing thread and stitch density to establish suitable ones for the achievement of quality in school uniforms. A total number of 290 specimens were used. Washed specimens were subjected to three cycles of washing using Launder-Ometer (Gyrowash 315) and seam strength, efficiency and elongation were evaluated. Means of the attributes were determined and analysis of variance at $\mathbf{0 . 0 5}$ alpha level was used for hypotheses testing. Sewing thread brand B in 14 stitches per inch (spi) provided greater seam strength, efficiency and elongation before and after washing.
\end{abstract}

Keywords - Ghanaian Uniform Fabric, Laundering Effects, Seaming Attributes

\section{Introduction}

Seams are formed when two or more pieces of fabrics are held together by stitches and they form the basic elements whose quality has significant influence on apparel products [1].

DOI: $10.18421 /$ SAR42-07

https://doi.org/10.18421/SAR42-07

Corresponding author: Patience Danquah Monnie, Department of Vocational and Technical Education, University of Cape Coast, Cape Coast, Ghana.

Email: patience.danquah@ucc.edu.gh

Received: 24 May 2021.

Revised: 20 June 2021.

Accepted: 25 June 2021.

Published: 27 June 2021.

(C) 2021 Patience Danquah Monnie et al; published by UIKTEN. This work is licensed under the CC BY-NC 4.0 licence.

The article is published with Open Access at www.sarjournal.com
The seam of a garment is noted to be the most important parameter to maintain the product's quality [2], [3]. Poor quality seams are likely to affect the usability of a clothing item. The quality attributes of seams include strength, elongation/elasticity, durability, slippage, puckering, efficiency, appearance and yarn severance [3], [4], [5], [6], [7], [8], [9]. These are dependent on the interrelationship among the type and weight of fabric, needle, size of the sewing thread, stitches per inch $/ 2.5 \mathrm{~cm}$ (SPI) and type of seam selected [10], [11], [13], [14].

It is however noted that the end-use of a seamed product usually determines which of the parameters is the most important to be evaluated in the article of clothing [3], [10]. For instance, seams in school uniforms are to have high seam strength to be able to withstand the frequent washing procedures due to the activities of school children such as play. Some characteristics of fabrics that influence seaming attributes include weight, thickness, strength and shrinkage [12]. Thus seaming performance depends on the stitches and the fabric that is stitched as well. There is therefore the need to determine fabric attributes in order to select appropriate seaming factors such as threads and stitch densities to achieve good quality garments.

Garments, usually go through repeated laundering, which may result in change in quality and performance of the sewn product [14]. A number of studies have observed water quality, detergent type, and drying conditions as significant variables that affect the amount of damage to fabrics and seams in garments during care [15], [16], [17], [18], [19]. Garment laundering is largely an applied care procedure employed for the care and performance evaluation of clothing [20]. For instance, [14], [21] stated that conditions of washing and dry cleaning are factors used to assess the properties of seams in apparels. The seams in garments are supposed to remain for the life of garment in order to sustain the usability of the garment.

School uniforms are washed during use and this care procedure may influence their overall performance. There is, therefore, the need to evaluate the seams used for their manufacture during care procedures to determine how well they would 
maintain their overall quality. Several studies have been conducted to establish seaming quality after laundering in some fabrics, but that of the fabrics used for uniforms by Ghanaian public basic school pupils have not received much attention. However, seam failure is one of the problems faced by school pupils in Ghana. For example [14] observed interaction of sewing parameters and laundry on seams performance of selected suiting fabrics and observed that reduction in seam strength and efficiency due to laundering was greater for coarser sewing threads. Laundering was noted to be a major factor that affected the performance of seams as it affected seam strength, efficiency and elongation [22], [23]. In this study, the seaming attributes of a suitable fabric for Ghanaian public basic school uniforms was evaluated.

The aim of the study was to establish if there were any differences among the number of times of washing and seam strength, efficiency and elongation for a suitable fabric for school uniform production. The outcome of the study was anticipated to aid in determining sewing threads and stitch densities that can withstand laundering to help achieve quality of seams in uniform fabrics and serve as literature for further studies.

The study was guided by the following hypotheses:

1. There is no significant difference among wash cycles and the seam strength of a suitable fabric for Ghanaian public basic schools uniforms.

2. There is no significant difference among wash cycles and the seam efficiency of a suitable fabric for Ghanaian public basic schools uniforms.

3. There is no significant difference among wash cycles and the seam elongation of a suitable fabric for Ghanaian public basic schools uniforms.

\section{Research Methodology}

\subsection{Materials}

\subsubsection{Fabric Sample}

A prior research was undertaking where a number of uniform fabrics used for public basic school uniforms were evaluated among which a suitable one was determined. From the results, a fabric brand was found to be the best suited for school uniforms in the Ghanaian climate. Based on that, 11 metres of the fabric brand, sandy brown colour, was purchased for the study. The procedures used to evaluate the laundering effect on seaming attributes can as well be employed to test the other colour of the fabric brand (chocolate 4/saddle brown colour).

\subsubsection{Sewing Threads for Stitching Seams}

Two most commonly used imported brands of polyester sewing threads for garment production in Ghana were bought from the market and labelled A and $\mathrm{B}$ for ethical reasons.

\subsubsection{Soap for Washing Tests}

Key bar soap, produced by Uniliver, Ghana Limited, was purchased from the market and used for washing tests. [16] in a study on the effect of sunlight and drying methods on the strength of Ghanaian Real Wax printed fabrics, used key soap. They stated that key soap is one of the popular soaps used by Ghanaians for washing coloured clothes. In addition, key soap is found to be one of the most popular soaps, least expensive and are mostly available in the Ghanaian markets [24]. The soap washes great and perfect for coloured fabrics [25]. These statements influenced its selection for this study.

\subsection{Methods}

\subsubsection{Preparation of Specimens for data collection}

Following ISO 13935-1 [26], 40 pieces of fabric specimens (20 in warp, 20 in weft), each measuring $19 \mathrm{~cm} \times 42 \mathrm{~cm}$ were randomly cut from the 11 metres of the fabric sample. The specimens were folded in half with the fold parallel to the $42 \mathrm{~cm}$ direction and the seams made in this direction as indicated by [26]. The seams were made using the 301 lock-stitch which is the most common stitch used by seamstresses in Ghana, and [27] also states is the standard laboratory stitch used for testing seam quality. The butterfly hand sewing machine with needle size 14 was used to make plain seam (301SSa-1 seam type). The sewing thread brands labelled $\mathrm{A}$ and $\mathrm{B}$ were used as both upper and under threads in stitching using stitch densities, 10,12 and 14 with seam allowance of $2 \mathrm{~cm}$. The stitch densities were selected based on the recommended range for medium weight fabrics which ranges from 12-14 stitches per inch [28], [29].

Out of 40 stitched specimens, 240 specimens, measuring $15 \mathrm{~cm} \times 6 \mathrm{~cm}$ were prepared and used for testing. It was indicated in [26] that either warp, or weft seams or both could be tested. The researchers decided to test both, as both directions of seams are seen in uniforms as in side seams and shoulder seams. For testing fabric tensile properties, ISO 13934-1 [30], procedure was followed and 40 specimens prepared.

All specimens for the investigations were conditioned for 24 hours in a relaxed state at a relative humidity of $65 \pm 2 \%$ and a temperature of $21^{\circ} \pm 1^{\circ} \mathrm{C}$ [26]. The following parameters were determined: 


\subsubsection{Seams Strength, Elongation and Efficiency}

The tensile testing machine (Mark-10 Force Gauge Model M5-500) was employed in testing seam strength and elongation with the gauge length of $100 \mathrm{~mm}$ and the rate of extension or speed of $20 \mathrm{~mm} /$ minute. The force at break (strength) was recorded in Newton $(\mathrm{N})$ and the extension at break (elongation) recorded in millimetres for each specimen in both the warp and the weft directions after each wash cycle. These were done for the unwashed specimens as well. Seam elongation was calculated as: $\varepsilon=(\Delta \mathrm{L} / \mathrm{L}) \times 100$ [2], [29], [31]. Seam efficiency was calculated using the formula adopted from [2], [12], [29], [31] as:

$$
\begin{aligned}
& \text { Where, } \quad \mathrm{S}_{\mathrm{E}}=\frac{\mathrm{S}_{\mathrm{S}}}{\mathrm{F}_{\mathrm{S}}} \times 100 \\
& \mathrm{~S}_{\mathrm{E}}=\text { Seam Efficiency } \\
& \mathrm{S}_{\mathrm{s}}=\text { Seam strength } \\
& \mathrm{F}_{\mathrm{s}}=\text { Fabric strength }
\end{aligned}
$$

\subsubsection{Sewing threads linear density}

The linear density of the sewing threads was determined following ISO standard (ISO 2060) [32]. One reel of each brand of the sewing thread was used. The length of each brand of thread was determined with the aid of a thread reel. After that, the full length of each brand of thread was weighed to establish their weights in grams. The linear density of each sewing thread brand was calculated with the equation:

$$
\mathrm{Ttc}=\frac{\mathrm{mc} \times 1000}{\mathrm{~L}}
$$

Where $\mathrm{mc}=$ the mass, in grams, of the test skein

$\mathrm{L}=$ the length, in meters of the test skein [32].

\subsubsection{Washing and Drying procedures}

The procedures used by Ghana Standards Authority (GSA) Textile testing Laboratory for preparation of soap solution and washing were followed. A stock solution of 39 grams of soap dissolved in $9.6 \mathrm{~L}$ of water was prepared and was able to wash all the specimens in the three wash cycles. The Standard Launder-Ometer (Gyrowash 315) with the solution prepared from the key soap was used to wash the specimens. Washing was at $60^{\circ} \mathrm{C}$ temperature for 30 minutes followed by rinsing in each wash cycle. The washed specimens were dried at room temperature and tested for the various parameters without ironing.

\subsection{Data Analysis}

The Predictive Analytical Software (SPSS) for Windows version 22 was employed in the analysis of the data. Means and standard deviations of the tested parameters were calculated and inferential statistics (Analysis of Variance at 0.05 alpha levels) was used for testing the hypotheses.

\section{Results}

The fabric used for the study was medium weight with a plain weave of $1 \times 1$ repeat in both directions. It was cotton and polyester blend with a higher percentage of polyester and higher yarn count, linear density and strength in the warp direction than the weft. However, for elongation, the weft direction was greater than the warp. With regard to the sewing threads, brand $\mathrm{B}$ had a higher linear density than A (Table 1).

Table 1. Attributes of sampled fabric and sewing threads

\begin{tabular}{lccc}
\hline Attributes & N & Mean & SD \\
\hline Fabric yarn count & & & \\
Warp & 5 & 62 & 0.894 \\
Weft & 5 & 46 & 1.289 \\
Fabric Weight & 5 & $138 \mathrm{~g} / \mathrm{m}^{2}$ & 0.837 \\
Yarn linear density & & & \\
Warp & 1 & $78 \mathrm{Tex}$ & - \\
Weft & 5 & $42 \mathrm{Tex}$ & 0.548 \\
Breaking strength & & & \\
Warp & 5 & $401 \mathrm{~N}$ & 49.193 \\
Weft & 5 & $372 \mathrm{~N}$ & 36.594 \\
Breaking Elongation & & & \\
Warp & 5 & $31 \%$ & 3.422 \\
Weft & 5 & $44 \%$ & 6.589 \\
Sewing Threads & A & B & \\
Linear density & 30Tex & $44 \mathrm{Tex}$ & \\
\hline
\end{tabular}

$N=$ Number of specimens; $M=$ Mean; $S D=$ Standard Deviation

\subsection{Hypothesis 1}

Significant difference was found between the number of times of washing and seam strength in the warp seams $(F=4.721, d f=3, p=0.004)$, but not in the weft seams $(F=0.364, d f=3, \quad p=0.779)$, which is shown in Table 2. For the weft seams, the mean strength values in Table 2 indicate that, seam strength decreased after first wash, decreased after second wash, but increased after $3^{\text {rd }}$ wash. Post Hoc results in the warp seams showed significant differences between unwashed $\times$ first wash, unwashed $\times$ second wash and unwashed $\times$ third wash. Figure 1 illustrates the trend of increase or decrease in seam strength as wash cycle progressed. It can be noted that, the warp seams stitched with the two sewing thread brands (A and B) in 10 SPI decreased in strength after $1^{\text {st }}$ wash, but increased in strength 
after the $2^{\text {nd }}$ and $3^{\text {rd }}$ washes. Warp seams stitched with sewing thread brand B and weft seams stitched with sewing thread brand $\mathrm{A}$ in 12 SPIs experienced a trend of decrease after each wash cycle, shown in Figure 1. The weft seam stitched with thread brand B in 14 SPI decreased in strength after first wash, decreased after second wash and increased after the third wash, but had the greatest strength in all the wash cycles, shown in Figure 1.

\subsection{Hypothesis 2}

With regard to seam efficiency, significant difference was established between the number of times of washing (wash cycle) in both the warp $(F=2.920, \quad d f=3, \quad p=0.037)$ and weft seams $(F=2.703, d f=3, p=0.049)$, which is shown in Table 2 . Table 2 shows that on the average seam efficiency decreased after the first wash, increased after second wash and increased again after the third wash in both warp and weft seams. Post Hoc analysis indicated that seams in the weft direction had significant differences between unwashed $\times$ first wash only.

The trend of increase or decrease in seam efficiency as wash cycle progressed is illustrated in Figure 2. The warp seams stitched with sewing thread brands A and B and weft seams stitched with sewing thread brand B in 10 SPI as well as weft seams stitched with sewing thread brand A in 12 SPI, decreased in efficiency after $1^{\text {st }}$ wash, decreased after $2^{\text {nd }}$ wash, but increased after $3^{\text {rd }}$ wash, shown in Figure 2. Warp seams stitched with sewing thread brand B in 12 SPI and weft seams stitched with sewing thread brand A in 10 SPI experienced a trend of decrease after the first and second washes, but increased after the third wash cycle, shown in Figure 2. Seams stitched with sewing thread brand B in 14 SPI both in the warp and weft had a trend of decrease, increase, and increase after each of the wash cycles, but obtained the greatest percentage efficiency values among their direction of seams throughout the wash cycles, which is shown in (Figure 2).

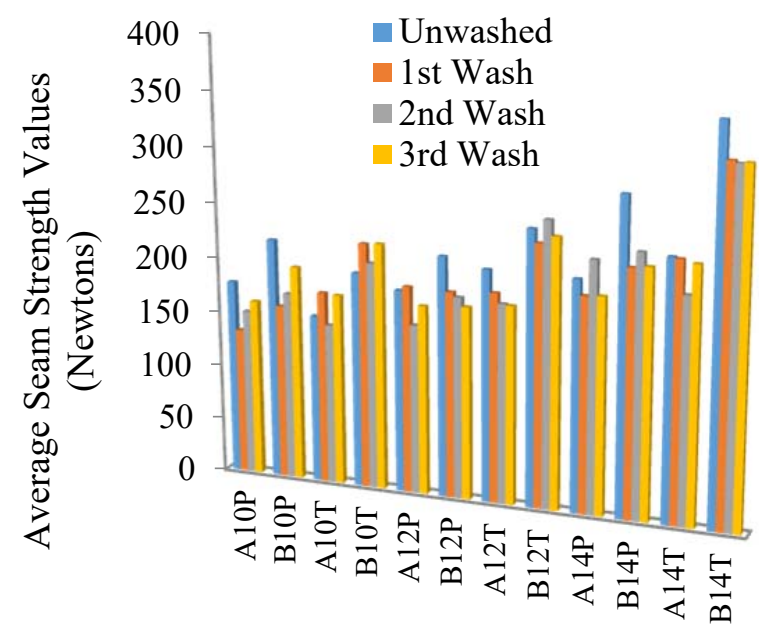

Sewing Thread Brands /Stitch Densities

Figure 1. Differences between wash cycles in terms of seam strength

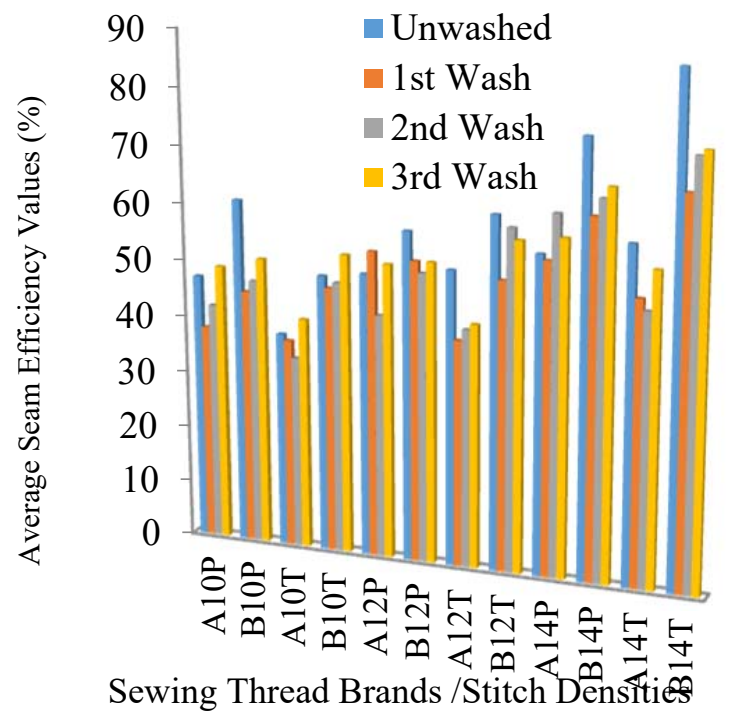

Figure 2. Differences between wash cycles in terms of seam efficiency

Table 2. Means, Standard Deviations, F-values and P-values for seam strength, efficiency and elongation by three wash cycles

\begin{tabular}{|c|c|c|c|c|c|c|c|c|c|c|c|c|}
\hline \multirow[b]{2}{*}{ Parameter } & \multirow{2}{*}{$\begin{array}{l}\text { Wash } \\
\text { Cycle } \\
\end{array}$} & \multicolumn{2}{|c|}{ Unwashed } & \multicolumn{2}{|c|}{$1^{\text {st }}$ Wash } & \multicolumn{2}{|c|}{$2^{\text {nd }}$ Wash } & \multicolumn{2}{|c|}{$3^{\text {rd }}$ Wash } & \multirow{2}{*}{ df } & \multirow{2}{*}{$F$} & \multirow{2}{*}{$p$-value } \\
\hline & & $\mathrm{M}$ & SD & $\mathrm{M}$ & SD & M & SD & $\mathrm{M}$ & SD & & & \\
\hline \multicolumn{13}{|c|}{ Strength (Newton) } \\
\hline Warp & & 215 & 44.531 & 181 & 35.688 & 187 & 40.392 & 188 & 34.269 & 3 & 4.721 & $0.004 *$ \\
\hline Weft & & 233 & 64.904 & 229 & 48.941 & 218 & 58.243 & 229 & 50.703 & 3 & 0.364 & 0.779 \\
\hline $\begin{array}{c}\text { Efficiency (\%) } \\
\text { Warp }\end{array}$ & & 58 & 12.167 & 51 & 10.215 & 52 & 11.191 & 57 & 10.356 & 3 & 2.920 & $0.037 *$ \\
\hline Weft & & 58 & 16.229 & 49 & 10.425 & 51 & 13.699 & 54 & 12.014 & 3 & 2.703 & $0.049 *$ \\
\hline $\begin{array}{c}\text { Elongation (\%) } \\
\text { Warp }\end{array}$ & & 34 & 5.393 & 38 & 6.574 & 41 & 9.095 & 39 & 6.479 & 3 & 4.311 & $0.004^{*}$ \\
\hline Weft & & 23 & 6.874 & 23 & 6.323 & 23 & 5.399 & 23 & 6.026 & 3 & 0.031 & 0.993 \\
\hline
\end{tabular}




\subsection{Hypothesis 3}

Significant differences existed between the number of times during the washing and elongation in warp $(F=4.311, d f=3, p=0.004)$ seams, but not weft seams $(F=0.031, d f=3, p=0.993)$, shown in Table 2. The mean values in Table 2 show that, the weft seams maintained their elongation throughout the wash cycles. Further analysis of the data to determine between group differences in the warp seams revealed that differences were significant between $2^{\text {nd }}$ wash and unwashed specimens only.

Figure 3 illustrates that warp and weft seams stitched with sewing thread brand $\mathrm{A}$ in 10 SPI decreased in elongation after the first wash, increased after second wash, but reduced after third wash. Warp seams in 10 SPI stitched with brand B sewing thread increased in elongation throughout the wash cycles, shown in Figure 3. Weft seams in 12 SPI stitched with brand B sewing thread increased in elongation after the first wash but maintained the same level after second and third washes, shown in Figure 3. Warp seams stitched with the two brands of sewing threads (A and B) in 14 SPIs experienced a trend of increase, increase and decrease after each wash cycle, which is shown in Figure 3. The warp seam stitched with sewing thread brand B in 14 SPI however, had the highest percentage elongations throughout the wash cycles followed by the warp seams stitched with brand A sewing thread in 14 SPI, also shown in Figure 3.

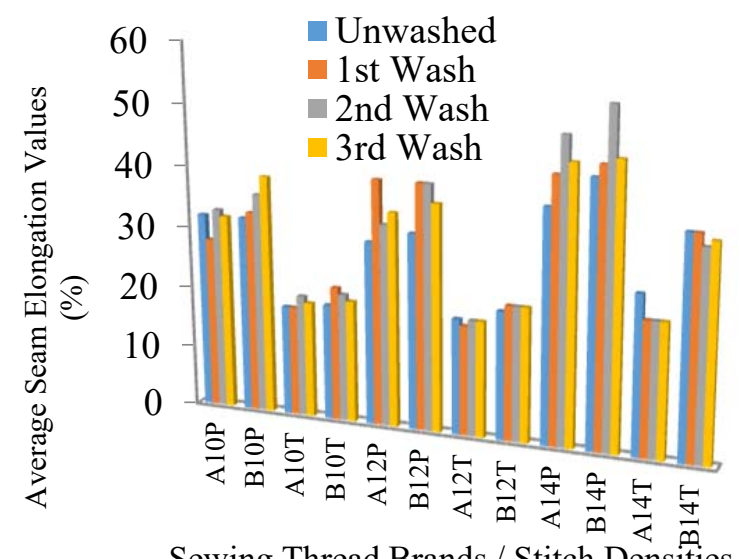

Sewing Thread Brands / Stitch Densities

Figure 3. Differences between wash cycles in terms of seam elongation

\section{Discussion}

On the whole, it can be stated that, looking at Figure 1 differences did exist between the number of times of washing and seam strength of all the seams stitched with the two thread brands in the three SPIs. [14] found reduction in seam strength as a result of laundering with the reduction being greater for coarser sewing threads, but the same cannot be said in this current study due to the trend of increase or decrease seen in the sewing threads. In addition, force at break increased on laundering with the change occurring more in seams stitched with coarser sewing thread [33]. In this current work, Figure 1 reveals that the brand $\mathrm{A}$ which is deduced from its linear density value as being a fine thread had increase in strength after the third washing in most of the seams. This is contrary to [33].

For seam efficiency, Table 2 shows that it varied in both directions as wash cycle progressed with the unwashed specimens in both directions having the greatest percentage efficiencies followed by third wash in both directions. The finding is similar to [22] who found significant effect of laundering on seam efficiency. The seam efficiency values obtained from the wash cycles ranged from $40 \%$ to $59 \%$ indicating that the fabric was stronger than the seams after each wash cycle as observed in Table 2. The current result is somewhat dissimilar to what [23] observed that seam efficiency reduced with increase in the number of washes. This is stated because Figure 2 portrays that seam efficiency after third washing increased for all seams in both sewing thread brands and SPIs in both directions except for the seams stitched with brand B in 12 SPI and brand A in 14 SPI in the weft direction. Another observation made from Figure 2 is that, amongst the weft seams, the ones stitched with thread brand B had high percentage efficiencies throughout the wash cycles. Surprisingly, the weft seam stitched with brand B sewing thread in 14 SPI obtained the highest seam efficiency throughout the wash cycles compared to all the other seams in both warp and weft directions. For the warp seams, the one stitched with sewing thread brand B in 14 SPI gained the highest seam efficiency values throughout the wash cycles. In all, the seams in the thread brand B especially those in the 14 SPI performed well with regard to seam efficiency throughout the wash cycles, shown in Figure 2. This shows that when the thread brand B with the 14 SPI is used in making seams in the suitable school uniform fabric, it would perform satisfactorily during use and after care. With regard to seam elongation, it can be seen from the mean scores in Table 2 that in the warp seams, elongation increased after first and second washes and decreased after the third wash.

For the weft seams, elongation was maintained throughout the wash cycles. [22] found that laundering had significant effect on seam elongation which is similar to the findings of this study in the warp direction. In addition, Figure 3 illustrates that there were variations in the number of times of washing with regard to seam elongation.

For instance, warp seam stitched with sewing thread brand B in 10 SPI experienced increase in seam elongation throughout the wash cycle. 
In general, from Figure 3, the weft seams stitched with thread brand A in 10 and 12 SPIs had the lowest percentage elongations all through the wash cycles.

Figure 3 shows that weft seam stitched with thread brand $\mathrm{B}$ in 14 SPI had the highest percentage elongations all through the wash cycles compared to other weft seams. Interestingly, the warp seam stitched with sewing thread brand B in 14 SPI obtained the highest elongation values in all the wash cycles compared to all the other seams. Generally, seams in the brand B thread performed well in terms of seam elongation in all the wash cycles, which is shown in Figure 3. Seam elongation for warp seams throughout the wash cycles seemed higher than the weft seams; also see Figure 3. The trend may be due to the direction of the fabric where force is applied for each seam. For the warp seams, they are parallel to the warp yarns of the fabric and so the force is applied on the weft yarns of the fabric which are known to stretch more compared to warp yarns. This proves the generally accepted idea that weft yarns stretch more than warp yarns as it shows that the fabric elongation also contributes to the seams' elongation.

\section{Conclusion and Recommendations}

From the results of the study, it can be concluded that laundry has effect on seaming attributes of the evaluated fabric. The level of effect on seaming attributes depends on the type of sewing thread and stitch density used in seaming. It was observed that differences existed among the wash cycles used for the study in terms of seam strength, efficiency and elongation of all the seams. However, sewing thread brand B in the 14 SPI provided greater seam strength, efficiency and elongation before and after washing, which shows that they are likely to perform satisfactorily in the evaluated suitable fabric for Ghanaian public basic school uniforms during the use and after the care. The sewing thread brand $\mathrm{B}$ with the 14 SPI is recommended for the construction of seams in the evaluated suitable fabric for Ghanaian public basic school uniforms. Garment manufacturers have to pay much attention to the selection of sewing threads and stitch densities used in garment construction as they can influence the behaviour of seams during use and after care of the garments. Further research is suggested to evaluate more sewing threads, stitch densities and laundry procedures to establish other threads that can also help achieve quality in school uniforms.

\section{References}

[1]. Abou Nassif, N. A. (2013). Investigation of the effects of sewing machine parameters on the seam quality. Life Science Journal, 10(2), 1427-1435.

[2]. LaPere, C. (2006). The Effects of Different Fabric Types and Seam Designs on the Seams [sic] Efficiency. Retrieved from:

https://commons.emich.edu/cgi/viewcontent.cgi?articl $\mathrm{e}=1052$ \&context=honors [accessed: 15 April 2021].

[3]. Mukhopadhyay, A., Chatterjee, A., \& Ahuja, T. (2014). Seam performance of the inseam of a military trouser in relation to garment fit. Textiles and Light Industrial Science and Technology, 3, 29-36.

[4]. Bharani, M., \& Mahendra, G. R. V. (2012). Characterization of seam strength and seam slippage of PC blend fabric with plain woven structure and finish. Research Journal of Recent Sciences, 1(12), 714.

[5]. Carr, H. and Latham, B. (1994). The technology of clothing manufacturing. Oxford: Blackwell Science Publications.

[6]. Cheng, K. P. S. and Poon, K. P. W. (2002). Studies on the seam properties of some selected woven fabrics. Textile Asia, 33(3), 30-34.

[7]. Dobilaite, V., \& Juciene, M. (2006). The influence of mechanical properties of sewing threads on seam pucker. Science and Technology, 18(5), 335-345.

[8]. Gurarda, A., \& Meric, B. (2007). The effects of elastane yarn type and fabric density on sewing needle penetration forces and seam damage of PET/elastane woven fabrics. Fibres \& Textiles in Eastern Europe, (4 (63)), 73-76.

[9]. Midha, V. K., Mukhopadhyay, A., \& Kaur, R. (2011). An approach to seam strength prediction using residual thread strength. Research Journal of Textile and Apparel.

[10]. ASTM D6193 (2009). Standard practice for stitches and seams. Retrieved from:

http://www.astm.org/standards/D6193.htm. [accessed 20 May 2021].

[11]. American and Efird Inc. (2009). Seam engineering. Retrieved from:

https://www.fibre2fashion.com/industryarticle/110/seam-engineering.

[accessed 20 May 2021].

[12]. Choudhary, A. K., \& Goel, A. (2013). Effect of some fabric and sewing conditions on apparel seam characteristics. Journal of Textiles.

[13]. Gurarda, A. (2008). Investigation of the seam performance of PET/nylon-elastane woven fabrics. Textile Research Journal, 78(1), 21-27.

[14]. Mukhopadhyay, A., Sikka, M., \& Karmakar, A. K. (2004). Impact of laundering on the seam tensile properties of suiting fabric. International Journal of Clothing Science and Technology, 16(4), 394-403. 
[15]. Fianu, D. A., \& Adams, M. (1998). The effect of sunlight on the colour of Ghanaian cotton printed fabrics. Journal of Consumer Studies \& Home Economics, 22(1), 15-18.

[16]. Fianu, D. A., Sallah, R. A., \& Ayertey, A. (2005). The effect of sunlight and drying methods on the strength of Ghanaian Real Wax printed fabrics. International Journal of Consumer Studies, 29(1), 34-40.

[17]. Lee, Y. H., \& Kim, H. D. (2004). Dyeing properties and colour fastness of cotton and silk fabrics dyed withCassia tora L. extract. Fibers and Polymers, 5(4), 303-308.

[18]. Mikučionienè, D. (2004). The dimensional change of used pure and compound cotton knitwear. Materials Science, 10(1), 93-96.

[19]. Herath, C. N., \& Kang, B. C. (2009). Effect of washing cycles on behavior of core spun cotton/spandex interlock structures. Fibers and Polymers, 10(2), 209-216.

[20]. Koženiauskienė, J., \& Daukantienè, V. (2013). Influence of Laundering on the Quality of Sewn Cotton and Bamboo Woven Fabrics. Materials Science, 19(1), 78-82.

[21]. Germanova-Krasteva, D. and Petrov, H. (2007). Investigation on the seam's quality by sewing of light fabrics (Electronic version). International Journal of Clothing Science and Technology, 20, 57-64.

[22]. Shawky, M. (2013). Effect of Home Laundering on Sewing Performance of Cotton Fabrics. Journal of Basic and Applied Scientific Research,3(12), 457463.

[23]. Babu,V. R., Koushik, C. V. and Ramachandaran, T. (2009). Performance of polyester/cotton sewing threads on seam strength. IE (I) Journal-TX, 90, 1115.

[24]. Kwame, S. A. (2012). Effects of locally manufactured soaps on colour, strength and elongation of some selected Ghanaian printed cotton fabrics (Doctoral dissertation, University of Cape Coast).
[25]. Market Express. (2016). Key bar soap. Retrieved from: https://marketexpress.com.gh. [accessed: 16 May 2021].

[26]. International Organization for Standardization 13935-1 (2014). Seam tensile properties of fabrics and made-up textile articles. Part 1: Determination of maximum force to seam rupture using the strip method. Switzerland: International Organization for Standardization.

[27]. Olsen, T. (2008). Development in testing seams. Retrieved from: http://www.testingtextiles.com/index.php. [accessed: 10 May 2021].

[28]. Brown, P., \& Rice, J. (1998). Ready to wear apparel analysis. Upper Saddle River, NJ: Prentice Hall.

[29]. Chowdhary, U., \& Poynor, D. (2006). Impact of stitch density on seam strength, seam elongation, and seam efficiency. International Journal of Consumer Studies, 30(6), 561-568.

[30]. International Organization for Standardization 13934-1. (2013). Textiles- Tensile properties of fabrics-Part 1: Determination of maximum force and elongation at maximum force using the strip test method. Switzerland: International Organization for Standardization.

[31]. Sarhan, T. M. A. (2013). Interaction between sewing thread size and stitch density and its effects on the seam quality of wool fabrics. Journal of Applied Sciences Research, 9(8), 4548-4557.

[32]. International Organization for Standardization 2060 (1994). Textiles- yarn from packages: determination of linear density (mass per unit length) by the skein method. Switzerland: International Organization for Standardization.

[33]. Mukhopadhyay, A. (2008). Relative performance of lock stitch and chain stitch at the seat seam of military trouser. Journal of Engineered Fibers and Fabrics, 3, 21-24. 